\title{
CLS (Cyber Learning Santri): Optimalisasi Proses Pembelajaran Pondok Pesantren Salafiah sebagai Upaya Merealisasikan Visi Indonesia Maju Menuju Indonesia Emas 2045 (Studi Kasus: Pondok Pesantren Assalafiyah 1 Luwungragi Brebes)
}

\author{
Moh. Ali Muddin" ${ }^{* 1}$ Firmanda Dwi Septiawan² \\ ${ }^{1,2}$ Fakultas Ilmu Budaya, Universitas Airlangga, Surabaya, Indonesia \\ Email: ${ }^{1}$ moh.ali.muddin-2019@ fib.unair.ac.id, ${ }^{2}$ firmanda.dwi.septiawan-2019@ fib.unair.ac.id
}

\begin{abstract}
Abstrak
Pada tahun 2045 perekonomian dunia diperkirakan tidak lagi bergantung pada pergerakan ekonomi Amerika Serikat (AS). Namun diperkirakan akan berada di Asia, seperti China, India, Korea Selatan, Jepang dan Indonesia. Hal ini dikarenakan kawasan Asia yang terbantu oleh bonus/dividen demografi, salah satunya Indonesia yang akan masuk ke dalam jajaran negara di dunia dengan pertumbuhan ekonomi terbesar pada tahun 2045 mendatang. Namun dengan tingginya angka usia produktif yang mencapai $70 \%$ ini, belum tentu dapat menjamin bahwa Indonesia akan benar-benar dapat menikmati bonus demografi, hal ini dikarenakan pemerintah harus segera melakukan optimalisasi dengan investasi lebih besar pada pengembangan sumber daya manusia. Pangkalan Data Pondok Pesantren sebagai lembaga pendidikan mencatat sebanyak 12.688 pondok pesantren salafiyah yang tersebar di seluruh Indonesia. Dengan jumlah yang banyak inilah sangat amat disayangkan apabila belum ada sentuhan metode pembelajaran e-learning dengan memanfaatkan sekumpulan teknologi dan organisasi rantai berupa smart factory, CPS, IoT dan IoS. Mengingat berdasarkan survei penggunaan Teknologi Informasi dan Komunikasi oleh Pusat Penelitian dan Pengembangan Aplikasi Informatika dan Informasi dan Komunikasi Publik, Badan Penelitian dan Pengembangan Sumber Daya Manusia.
\end{abstract}

Kata kunci: Pendidikan, Pesantren, SDM, Teknologi

\begin{abstract}
In 2045, it is estimated that the world economy will no longer depend on the economic movement of the United States (US). However, it is expected to be in Asia, such as China, India, South Korea, Japan and Indonesia. This is because the Asian region is helped by demographic bonuses/dividends, one of which is Indonesia, which will enter the ranks of countries in the world with the largest economic growth in 2045. However, with the high number of productive age reaching $70 \%$, it does not necessarily guarantee that Indonesia will actually be able to enjoy the demographic bonus, this is because the government must immediately optimize it with greater investment in human resource development. The Pondok Pesantren Database as an educational institution records as many as 12,688 salafiyah Islamic boarding schools spread throughout Indonesia. With this large number, it is very unfortunate if there is no touch of e-learning learning methods by utilizing a set of technologies and chain organizations in the form of smart factories, CPS, IoT and IoS. Considering that based on a survey of the use of Information and Communication Technology by the Center for Research and Development of Information and Communication Applications and Public Information, the Agency for Research and Development of Human Resources.
\end{abstract}

Keywords: Education, HR, Islamic Boarding School, Technology

\section{PENDAHULUAN}

Indonesia emas 2045 merupakan salah satu harapan besar bangsa Indonesia untuk mencapai masa kejayaannya, terlepas dari waktu dimana Indonesia telah merdeka selama 100 tahun lamanya. Pada tahun ini dilansir dari Badan Kependudukan dan Keluarga Berencana Nasional (BKKBN) Juni 2017, $70 \%$ jumlah penduduk Indonesia akan berada dalam usia produktif yaitu antara umur 15-64 tahun sedangkan $30 \%$ sisanya merupakan penduduk yang tidak produktif, yaitu berada pada usia dibawah 14 tahun dan diatas 65 tahun. 
Pada tahun 2045 perekonomian dunia diperkirakan tidak lagi bergantung pada pergerakan ekonomi Amerika Serikat (AS). Namun diperkirakan akan berada di Asia, seperti China, India, Korea Selatan, Jepang dan Indonesia. Hal ini dikarenakan kawasan Asia yang terbantu oleh bonus/dividen demografi, salah satunya Indonesia yang akan masuk ke dalam jajaran negara di dunia dengan pertumbuhan ekonomi terbesar pada tahun 2045 mendatang. Pada tahun 2045 mendatang Indonesia diperkirakan akan mencapai 309 juta orang dengan angka Pendapatan Domestik Bruto (PDB) mencapai 29 ribu dolar AS per tahun. Dengan kondisi ini, Indonesia mempunyai peluang untuk dapat menikmati 'bonus demografi' yaitu percepatan pertumbuhan ekonomi yang diakibatkan oleh berubahnya struktur umur penduduk yang ditandai dengan menurunnya rasio ketergantungan (dependency ratio) penduduk non-usia kerja kepada penduduk usia kerja. Di Indonesia, rasio ketergantungan telah menurun dan melewati batas di bawah 50\% pada tahun 2012 lalu dan mencapai titik terendah sebesar 46,9\% antara tahun 2028 dan 2031.

Namun dengan tingginya angka usia produktif yang mencapai $70 \%$ ini, belum tentu dapat menjamin bahwa Indonesia akan benar-benar dapat menikmati bonus demografi, hal ini dikarenakan pemerintah harus segera melakukan optimalisasi dengan investasi lebih besar pada pengembangan sumber daya manusia. Menurut data Proyeksi Penduduk Indonesia 2010-2035 oleh Badan Perencanaan Pembangunan Nasional 2013, diketahui bahwa masa maksimum bonus demografi ini akan terjadi pada 2028, 2029, 2030 dan 2031. Selama itu, prosentase penduduk usia muda dan produktif akan mencapai 46,7\%. Sehingga apabila berkaca dari hal ini, Indonesia memiliki waktu selama 10 tahun mendatang untuk melakukan investasi habis-habisan di bidang sumber daya manusia hingga memasuki tahun 2031.

Menjadi langkah keharusan yang wajib dijalankan agar dapat merealisasikan bonus demografi dengan baik, Presiden Joko Widodo telah merumuskan tujuh butir visi impiannya untuk Indonesia pada tahun 2085 nanti. Impian ini ditulis langsung oleh beliau saat mengunjungi Merauke, Papua, pada 30 Desember 2015 sebagai berikut.

a. Sumber Daya Manusia yang kecerdasannya mengungguli bangsa-bangsa lain di dunia.

b. Masyarakat Indonesia yang menjunjung tinggi pluralisme, berbudaya, religius, dan menjunjung tinggi nilai-nilai etika.

c. Indonesia menjadi pusat pendidikan, teknologi, dan peradaban dunia.

d. Masyarakat dan aparatur pemerintah yang bebas dari perilaku korupsi.

e. Terbangunnya infrastruktur yang merata di seluruh Indonesia.

f. Indonesia menjadi negara yang mandiri dan negara yang paling berpengaruh di Asia Pasifik.

g. Indonesia menjadi barometer pertumbuhan ekonomi dunia.

Melihat dari butir ketiga inilah, kemudian terdapat alasan bahwa belum ada kesinambungan yang terjalin untuk dapat meningkatkan sumber daya manusia dengan fakta yang ada, karena belum sepenuhnya pendidikan di Indonesia telah memanfaatkan teknologi untuk mempermudah proses belajar mengajar, salah satunya ialah pondok pesantren salafiah. Sehingga apabila hal ini terus menerus terjadi maka proses perealisasian bonus demografi ini akan menjadi terhalang.

Menurut Pangkalan Data Pondok Pesantren, tercatat sebanyak 12.688 pondok pesantren salafiyah yang tersebar di seluruh Indonesia. Dengan jumlah yang banyak inilah sangat amat disayangkan apabila belum ada sentuhan metode pembelajaran $e$-learning dengan memanfaatkan sekumpulan teknologi dan organisasi rantai berupa smart factory, CPS, IoT dan IoS. Mengingat berdasarkan survei penggunaan Teknologi Informasi dan Komunikasi oleh Pusat Penelitian dan Pengembangan Aplikasi Informatika dan Informasi dan Komunikasi Publik, Badan Penelitian dan Pengembangan Sumber Daya Manusia Kementerian Komunikasi dan Informatika Republik Indonesia tahun 2017, tercatat pengguna gadget dengan rentang usia 9-19 tahun mencapai $65,34 \%$ dan usia 20-29 tahun mencapai 76,95\% atau pada jenjang pendidikan SD mencapai 40,87\%, SMP 59,89\%, SMA 79,56\%, dan Diploma/S1 93,02\%.

Dari permasalahan dan beberapa data yang dianggap perlu dimanfaatkan inilah, peneliti dalam hal ini kemudian memiliki gagasan berupa "CLS (Cyber Learning Santri) : Optimalisasi Proses Pembelajaran Pondok Pesantren Salafiah Sebagai Upaya Merealisasikan Visi Indonesia Maju Menuju Indonesia Emas 2045 (Studi Kasus: Pondok Pesantren Assalafiyah 1 Luwungragi Brebes)" yang diharapkan dapat menjadikan salah satu misi untuk merealisasikan visi tersebut, dengan meningkatkan kualitas sumber daya manusia bangsa Indonesia jauh lebih baik dengan tetap menjunjung nilai-nilai 
pluralisme, budaya, religi, dan etika yang selama ini ditekankan pada bangsa Indonesia agar dapat memasuki era bonus demografi dengan maksimal tanpa meninggalkan teknologi untuk mendukung jalannya peningkatan kualitas sumber daya manusia.

\section{METODE}

Metode yang digunakan dalam penelitian ini adalah metode dokumentasi dan wawancara terhadap narasumber yaitu salah satu pihak administrator pada bagian pendaftaran di pondok pesantren Assalafiyah 1 Luwungragi Brebes pada Minggu, 21 Maret 2021. Data penelitian yang didapatkan ini kemudian dikembangkan dengan melakukan literature study approach. Metode literature study approach adalah sebuah pendekatan studi kepustakaan dengan mengkaji berbagai informasi yang sesuai dengan permasalahan serupa. Informasi yang didapat berupa data yang bersumber dari buku referensi, artikel ilmiah, skripsi, tesis, disertasi, dan jurnal berskala nasional hingga internasional yang memiliki kesesuaian tema derajat dengan masalah pendidikan di pondok pesantren khususnya dalam model belajar dan mengajar.

\section{HASIL DAN PEMBAHASAN}

Seperti yang diungkapkan oleh Zahara Idris (1987), yang menjelaskan bahwa sistem merupakan suatu kesatuan yang terdiri atas komponen-komponen atau elemen-elemen atau unsur-unsur sebagai sumber-sumber yang mempunyai hubungan fungsional yang teratur, tidak sekedar acak yang saling membantu untuk mencapai suatu hasil. Maka dalam hal ini pula sistem pendidikan memiliki tujuan yang sama, yaitu untuk menghubungkan beberapa fungsi hingga dapat mewujudkan suasana belajar dan proses pembelajaran agar peserta didik secara aktif mengembangkan potensi dirinya untuk memiliki kekuatan spiritual keagamaan, pengendalian diri, kepribadian, kecerdasan, akhlak mulia, serta keterampilan yang diperlukan dirinya, masyarakat, bangsa dan negara.

Sistem pendidikan yang digunakan dalam pondok pesantren umumnya adalah dengan sistem asrama, di mana santri tinggal satu komplek bersama kyai, dan juga adanya pengajaran kitab-kitab klasik, yang berbahasa Arab yang tentunya dalam memahaminya diperlukan adanya metode-metode khusus yang menjadi ciri khas dari pondok pesantren.

Maka disinilah kami membentuk CLS (Cyber Learning Santri) dengan dorongan sederhana ingin memudahkan para santri agar dapat belajar jauh lebih mudah tanpa harus bertatap muka, juga menerapkan teknologi dalam menunjang kegiatan sehari-hari, dan secara tidak langsung dapat membantu pemerintah untuk merealisasikan visi Indonesia menuju Indonesia emas 2045.

Setelah ditemukannya berbagai problematika mengenai proses pembelajaran pondok pesantren khususnya di pondok pesantren Assalafiyah 1 Luwungragi Brebes, kemudian akan dikaji melalui analisis SWOT agar dapat mengetahui seberapa berpengaruhnya CLS (Cyber Learning Santri) untuk mengatasi problematika tersebut. Analisis SWOT adalah identifikasi berbagai faktor secara sistematis untuk merumuskan strategi perusahaan, dimana kita dapat mengetahui berbagai kelebihan maupun kekurangan yang ada, sehingga diperlukannya adanya analisis SWOT untuk mengetahui kelebihan dan kekurangannya (Rangkuti, 2014). Hasil analisis tersebut dapat dilihat pada Tabel 1.

Dalam proses pengimplementasian ide ini, diperlukan strategi lebih lanjut agar dapat mendukung pengembangan dan keberlanjutan aplikasi ini. Berikut strategi implementasi program aplikasi CLS.

a. Kerjasama antar lembaga pendidikan pondok pesantren yang berkaitan dengan ahli IT, Ilustrator, orangtua, perusahaan-perusahaan yang dapat mengembangkan aplikasi ini.

b. Mengadakan peluncuran secara resmi pada aplikasi ini dengan mengundang orang-orang berpengaruh pada masyarakat khususnya para ulama-ulama ternama.

c. Menggunakan slogan dan iklan yang unik dengan tokoh yang digemari oleh masyarakat melalui berbagai media secara berkala.

d. Terus menghadirkan fitur-fitur inovatif kedepannya sebagai upaya untuk memberikan penyegaran pada para santri.

e. Menjaga engagement dengan pengguna dengan memberi pelayanan secara maksimal, menerima respon, kritik dan masukan. 
Tabel 1. Hasil Analisis SWOT terhadap keberpengaruhan CLS (Cyber Learning Santri)

\begin{tabular}{|c|c|}
\hline \multicolumn{2}{|c|}{ ANALISIS SWOT } \\
\hline Kekuatan (Strength) & Kelemahan (Weaknesses) \\
\hline $\begin{array}{l}\text { 1. Menggabungkan konsep pembelajaran } \\
\text { dengan media gadget. }\end{array}$ & $\begin{array}{l}\text { 1. Pembiayaan untuk pembuatan aplikasi } \\
\text { yang mahal. }\end{array}$ \\
\hline $\begin{array}{l}\text { 2. Memiliki kapasitas penyimpanan aplikasi } \\
\text { yang cukup ringan. } \\
\text { 3. Terdapat fitur-fitur yang akan bermanfaat }\end{array}$ & $\begin{array}{l}\text { 2. Belum dikenalnya aplikasi CLS sehingga } \\
\text { membutuhkan media promosi dari berbagai } \\
\text { pihak. }\end{array}$ \\
\hline $\begin{array}{l}\text { layaknya sedang menjalani kegiatan santri } \\
\text { pada umumnya. }\end{array}$ & $\begin{array}{l}\text { 3. Diperlukannya persiapan yang matang, } \\
\text { karena adanya kemungkinan tujuan } \\
\text { pembelajaran tidak tercapai secara } \\
\text { maksimal. }\end{array}$ \\
\hline Peluang (Opportunities) & Ancaman (Threats) \\
\hline $\begin{array}{l}\text { 1. Jumlah pengguna gadget yang besar di } \\
\text { Indonesia termasuk dalam usia santri. } \\
\text { 2. Preferensi anak hingga remaja yang } \\
\text { menyukai gadget. }\end{array}$ & $\begin{array}{l}\text { 1. Banyaknya pesaing media pembelajaran } \\
\text { online yang telah diterapkan di berbagai } \\
\text { instansi pendidikan bukan pondok } \\
\text { pesantren. }\end{array}$ \\
\hline 3. Banyaknya pondok & 2. Anak dan santri kemungkinan akan lalai \\
\hline akan membuat munculnya CLS & menjalankan \\
\hline di pondok pesantren assalafiah & menggunakan gadget di luar kebutuhannya. \\
\hline Brebes. & $\begin{array}{l}\text { 3. Tingkat kejenuhan anak dan santri yang } \\
\text { tidak dapat diprediksi. }\end{array}$ \\
\hline
\end{tabular}

Demikian halnya dengan ditemukannya analisis SWOT ini kemudian dikembangkan lebih lanjut mengenai rancangan konsep dan desain dari aplikasi CLS yang nantinya akan memuat berbagai keperluan para santri Assalafiyah 1 Luwungragi Brebes dalam melakukan pembelajaran, khususnya oleh santri di pondok pesantren Assalafiyah 1 Luwungragi Brebes. Namun sebelum melangkah lebih jauh dalam hal desain dari aplikasi CLS yang akan dibuat, peneliti dalam hal ini melakukan interview pada Minggu, 21 Maret 2021 dengan bapak Ulil Abshor selaku salah satu pihak administrator pada bagian pendaftaran di pondok pesantren Assalafiyah 1 Luwungragi Brebes. Pada hasil interview tersebut kemudian ditemukan beberapa data pendukung mengenai kegiatan-kegiatan santri, kurikulum berupa kitab-kitab yang dipelajari dan tingkatan sekolah di pondok pesantren Assalafiyah 1 Luwungragi Brebes dengan rincian interview sebagai berikut.

Tabel 2. Hasil interview

\begin{tabular}{|c|c|c|}
\hline No. & Pertanyaan & Jawaban \\
\hline 1. & $\begin{array}{l}\text { Apa saja yang dipelajari dalam } \\
\text { pondok pesantren ini? }\end{array}$ & $\begin{array}{l}\text { "Pondok pesantren Assalafiyah l Luwungragi } \\
\text { Brebes ini mengajar } 2 \text { jenis kitab sebagai ciri dari } \\
\text { ponpes Salafiyah, yaitu Kitab Nahwu Shorof dan } \\
\text { Kitab Fiqih. Untuk list berupa apa saja kitab } \\
\text { tersebut akan saya kirim di chat zoom" }\end{array}$ \\
\hline 2. & $\begin{array}{l}\text { Bagaimana metode pembelajaran } \\
\text { yang ada di pondok pesantren } \\
\text { Assalafiyah } 1 \text { Luwungragi Brebes? }\end{array}$ & $\begin{array}{l}\text { "Disini diterapkan metode sorongan wetonan dan } \\
\text { metode klasikal, ini metode yang sudah lama ada di } \\
\text { tiap ponpes, jadi sifatnya benar tradisional" }\end{array}$ \\
\hline 3. & $\begin{array}{l}\text { Bagaimana jalannya proses } \\
\text { pembelajaran yang ada di pondok } \\
\text { pesantren Assalafiyah } 1 \text { Luwungragi } \\
\text { Brebes? }\end{array}$ & $\begin{array}{l}\text { "Ini variatif, tergantung kyai atau ustadz atau } \\
\text { ustadzah yang mengajar, tapi kebiasaannya santri } \\
\text { itu baca lalu dijelaskan sama beliau. Kadang ada } \\
\text { hafalan-hafalan lalu diberi tugas untuk mencari } \\
\text { makna dari apa yang dipelajari agar berguna buat } \\
\text { kehidupan setelah keluar dari ponpes ini" }\end{array}$ \\
\hline
\end{tabular}


4. Bagaimana tingkatan sekolah yang ada di pondok pesantren Assalafiyah 1 Luwungragi Brebes?

5. Bagaimana proses pembayaran yang ada di pondok pesantren Assalafiyah 1 Luwungragi Brebes?

6. Bagaimana pendapat bapak, apabila sistem pendidikan di pondok pesantren menerapkan modernisasi khususnya pada pondok Assalafiyah 1 Luwungragi Brebes?
"Mulai dari madrasah Diniyah di tingkatan ibtidaiyah, Tsanawiyah, dan Aliyah, dan punya kitab yang dipelajari berbeda"

"Biayanya variatif tiap santri, karena nanti ada pendataan untuk gaji orang tua saat awal melakukan pendaftaran di sini, pembayaran bisa dilakukan tiap tahun atau tiap bulan, tergantung orang tua masing-masing santri"

"Tidak ada yang salah dalam perencanaan sistem pendidikan, saya yakin kalau misal itu terjadi pasti ada faktor-faktor dan indikator yang melandasi lahirnya sistem pendidikan itu. Jadi menurut saya apabila modernasi pendidikan tidak merusak tatanan pola yang diberi pada santri, kemungkinan hal itu pasti tidak apa karena pendidikan dengan sistem modernisasi pasti dengan tujuan ingin mempermudah santri dan pengajar"

Setelah ditemukannya data lebih intens melalui wawancara, karena adanya pertemuan yang dilakukan oleh dua orang untuk bertukar informasi maupun suatu ide dengan cara tanya jawab, sehingga dapat dikerucutkan menjadi sebuah kesimpulan atau makna dalam topik tertentu Esterberg dalam Sugiyono (2015:72). Maka kemudian peneliti merancang sebuah desain dan isi yang ada dalam aplikasi CLS sebagai berikut.

1. Tampilan menu awal dimana santri dapat memasukkan nama lengkap dan nomor induk santri ketika sudah terdaftar dalam pondok pesantren Assalafiyah 1 Luwungragi Brebes.

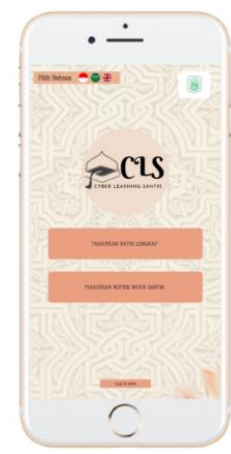

Gambar 1. Tampilan menu aplikasi CLS

2. Tampilan menu data santri, dimana mereka dapat melihat dan merubah apabila terdapat kesalahan didalamnya.

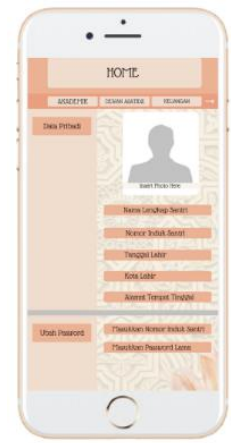

Gambar 2. Tampilan menu data santri aplikasi CLS 
3. Tampilan menu akademik, dimana mereka dapat melihat kitab apa saja yang akan dipelajari dalam kegiatan sehari-hari di pondok pesantren.

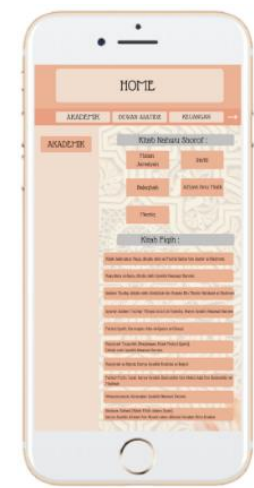

Gambar 3. Menu akademik aplikasi CLS

4. Tampilan menu dewan Asatidz, dimana mereka dapat melihat kyai, ustadz, ataupun ustadzah yang akan mengajarinya. Dalam menu ini terdapat opsi masuk ruang ajar yang mana ini akan menjadi media pembelajaran melalui virtual meeting antara santri dan pengajar (dewan Asatidz), dan ada juga fitur pesan dimana para santri dapat mengirimkan suatu pesan yang diinginkan.

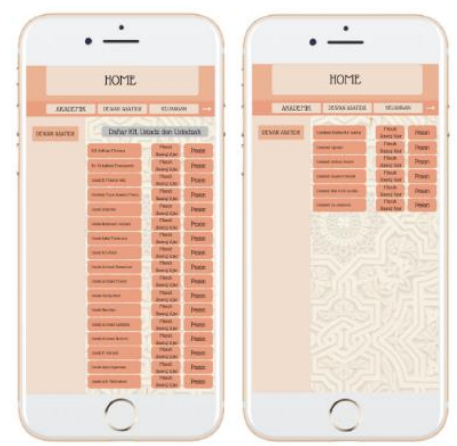

Gambar 4. Menu dewan Asatidz aplikasi CLS

5. Tampilan menu keuangan, dimana para santri dapat melihat mengenai riwayat pembayaran untuk biaya yang perlu dibayarkan atau yang akan dibayarkan.

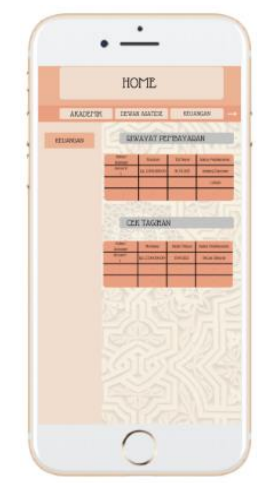

\section{Gambar 5. Menu keuangan aplikasi CLS}

6. Tampilan menu kalender, dimana para santri dapat melihat agenda-agenda, kegiatan maupun jadwal pelajaran yang akan dijalankan oleh mereka. Namun untuk menemukan menu ini mereka perlu swipe layar ponselnya bagian bar ke-2 ke arah kanan. 


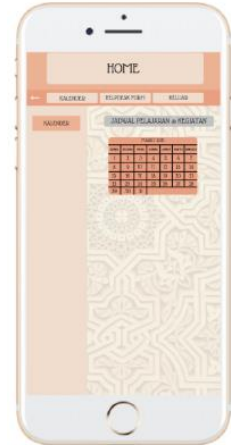

Gambar 6. Menu kalender aplikasi CLS

7. Tampilan menu Help Form, dimana para santri yang mengalami kendala saat menggunakan aplikasi CLS ini dapat melaporkannya disana, sehingga pihak IT yang bertugas akan segera memeriksanya di jam yang telah ditentukan.

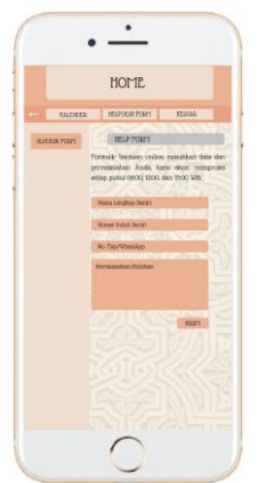

\section{Gambar 7. Menu Help Form aplikasi CLS}

Setelah dibuatnya desain prototype beserta isi yang ada, diharapkan aplikasi CLS dapat dilirik oleh berbagai investor dan ahli IT sesuai strategi implementasi program aplikasi CLS. Dengan pertimbangan berbagai analisis yang telah dilakukan beserta faktor pendukung antara lain.

a. Dukungan dari dewan pengasuh pondok pesantren berupa motivasi maupun materi,

b. Komitmen dan semangat yang tinggi dalam memajukan lembaga dari para pengurus pondok pesantren meskipun fasilitas tidak memadai,

c. Rasa optimisme yang tinggi dari berbagai pihak baik itu pengurus yayasan, dewan pengasuh, para pengurus maupun para santri,

d. Terbentuknya budaya auto kritik yang bersifat kontruktif di lingkungan pesantren,

e. Konsistensi dari para asatidz maupun para santri untuk mendukung pelaksanaan program pengembangan pendidikan Islam pada masyarakat,

f. Adanya pola pemikiran dari masyarakat umum (pengasuh, pengurus, santri, dan masyarakat) yang menganggap bahwa pendidikan Islam lebih penting dari pada pendidikan umum, dan

g. Kemampuan dari para pengasuh menjadi suriteladan, sehingga segala anjurannya dapat memotivasi orang lain.

Hal ini akan memperjelas arti penting dan tujuan dari modernisasi sistem pembelajaran dalam pondok pesantren ialah untuk menyempurnakan sistem pendidikan islam yang selama ini kurang berkembang dengan baik, sehingga melalui aplikasi CLS diharapkan dapat membantu para santri dalam proses belajar di lingkungan pondok pesantren salafiah, khususnya pondok pesantren Assalafiyah 1 Luwungragi Brebes.

\section{KESIMPULAN}

Berdasarkan hasil analisis pada bagian pembahasan yang telah dipaparkan, dapat disimpulkan 
bahwa aplikasi CLS (Cyber Learning Santri) diharapkan dapat menjadi solusi untuk menekan permasalahan pendidikan pondok pesantren agar dapat memasuki era bonus demografi dengan maksimal. Hal ini karena aplikasi CLS (Cyber Learning Santri) diyakini dapat membantu proses pengembangan kualitas sumber daya manusia khususnya para santri, mengingat perkembangan pendidikan saat ini yang terus digencarkan menggunakan teknologi dalam penerapannya. Penulis memberikan saran kepada setiap komponen yang terlibat didalamnya agar dapat merealisasikan aplikasi CLS (Cyber Learning Santri) dan kemudian mempromosikan aplikasi ini sebagai bentuk sinergi bersama guna mengatasi permasalahan pendidikan di kalangan pondok pesantren yang kurang menerapkan teknologi dalam proses belajar mengajar.

\section{DAFTAR PUSTAKA}

Affandi, M. (2001). Membedah Diskursus Pendidikan Islam. Jakarta: Kalimah.

Bawani, I. (1993). Tradisionalisme dalam Pendidikan Islam, Surabaya: Al-Ikhlas.

Daulay, H.P. (n.d). Pendidikan Islam dalam Sistem Pendidikan Nasional di Indonesia, Jakarta: Kencana David \& Rangkuti, F (2014). Manajemen Strategi, Edisi Sepuluh. Jakarta : Salemba Empat

Hidayah, Arini. (2012). Sejarah Pendidikan Islam di Indonesia, Bandung: PT. Raja Persada.

Idris, Z. (1987). Dasar-Dasar Pendidikan, Padang: Angkasa Raya.

Rianse, U. (2009). Metodologi Penelitian Sosial.Bandung: Alfabeta

Sugiyono. (2015). Memahami Penelitian Kualitatif. Bandung:

Alfabeta.Suharyat, Y. (2009). "Hubungan Antara Sikap, Minat Dan Perilaku Manusia". Jurnal Ilmiah Pendidikan Geografi. Vol. 1(3): hal 1-19.

Suismanto, (2004). Menelusuri Jejak Pesantren, Yogyakarta: Alief Press.

Kementerian Pendidikan dan Kebudayaan, (2014). Menyiapkan Generasi emas 2045: Memori Akhir Jabatan Menteri Pendidikan dan Kebudayaan 2010-2014.

Lampiran Peraturan Presiden Republik Indonesia Nomor 59 Tahun 2017 tentang Pelaksanaan Pencapaian Tujuan Pembangunan Berkelanjutan.

Mastuhu, (2004).Dinamika sistem pendidikan Pesantren, Jakarta:INIS

M. Hasyim, A. (2003). Menggagas Pesantren Masa Depan, Yogyakarta: CV. Qalam.

Martin Van Bruinessen, (1995). Kitab kuning,Pesantren, dan tarekat: Tradisi-tradisi Islam di Indonesia, Bandung: Mizan Anggta IKAPI.

Nasution, H. (1996). Pembaharuan dalam Islam; Sejarah pemikiran dan gerakan, Jakarta: Bulan Bintang. 